\title{
THE COMMODIFICATION OF BODY POSITIVITY: \\ CONSTRUCTING A NEOLIBERAL FAT CITIZENSHIP
}

by

Rhiannon Sian Downey, BSW, Lakehead University, 2019

BA, Dalhousie University, 2013

\author{
An MRP \\ presented to Ryerson University \\ in partial fulfillment of the \\ requirements for the degree of \\ Master of Social Work \\ in the program of \\ Social Work
}

Toronto, Ontario, Canada, 2020

(C) Rhiannon Sian Downey, 2020 


\section{AUTHOR'S DECLARATION}

I hereby declare that I am the sole author of this MRP. This is a true copy of the MRP, including any required final revisions.

I authorize Ryerson University to lend this MRP to other institutions or individuals for the purpose of scholarly research

I further authorize Ryerson University to reproduce this MRP by photocopying or by other means, in total or in part, at the request of other institutions or individuals for the purpose of scholarly research.

I understand that my MRP may be made electronically available to the public. 


\begin{abstract}
The Commodification of Body Positivity: Constructing a Neoliberal Fat Citizenship

Master of Social Work, 2020

Rhiannon Sian Downey

Social Work,

Ryerson University
\end{abstract}

From inspirational messages to celebrated pictures of cellulite and belly rolls, body positive content has become increasingly popular on social media platforms, particularly on image-based networking sites. With the rapid growth of communication technology, it is not surprising that social networking sites, such as Instagram, have become one of the most dominant and influential mediates to cultivating awareness, foster community, and advocate for social change. Instagram's transition to an advertising platform, however, has introduced a consumerist structure to user activity for corporations to better direct advertisements at target audiences. A once social movement advocating for the rejection of thin beauty ideals in favour of a more inclusive and positive conception of body image has felt the impact of commoditization on its message and advocates. Through Foucauldian Discourse Analysis, this research study seeks to analyze the impact of Instagram's transition to a commercialization platform on the self-representation of body positive advocates to better understand the influence of neoliberal and capitalist structures on social resistance movements and strategies. 


\section{ACKNOWLEDGEMENTS}

Considering this my terminal degree, with no plans to continue my education any further, I put this piece of research into perspective. While this research project assumed almost a year of my life, the journey to a complete master's degree took over ten years. Said journey included a variety of planning, missteps, successes, mistakes, failures, breakdowns, and breakthroughs. I would be remiss if I did not acknowledge all the people that helped me complete that journey. First and foremost, I would like to thank my mother, Katherine Downey. A quiet but unwavering force, I owe my choice of field to her. My mother's empathy and compassion know no bounds. All the breakthroughs over the last ten years I owe to her as she kindly, but firmly, encouraged me to lift myself back up and move forward. Her unconditional support took many forms over the years - late night editing, pep talks, drives to Staples, surprise gifts, chauffeuring, and hugs but ultimately, she was the reason I was able to complete this degree.

Over the last ten years a multitude of people have helped me in this journey. Friends, family, colleagues, mentors, clients, and loved ones all contributed a bit of themselves and should be recognized for it. My father, Keith Large, an expert in his own field, modeled a confident commitment to excellence that I try to mimic in my own work. Dealing with constant feelings of imposter syndrome, especially as I completed this research project, my father offered unwavering support as he confidently believed in my ability to complete this degree program. I've been blessed with friends who I gently refer to as my 'support bubble' - those who both protect me from the harsh realities of social work practice, and inspire me to continue working in the field I love. I am nothing without my support system, and I can't express how much I appreciate their support as I finish my post-graduate journey. 


\section{DEDICATION}

This piece of research is dedicated to all the radical fatties. I am your eternal student and grateful for the education and mentorship you've provided me. 


\section{TABLE OF CONTENTS}

CHAPTER ONE: INTRODUCTION

Page 1

CHAPTER TWO: LITERATURE REVIEW

Page 3

Neoliberal Construction of Fatness

Page 3

Consumer Activism

Page 5

History of the Fat Acceptance Movement

Page 9

Contemporary Body Positivity \& Social Media

Page 11

CHAPTER THREE: THEORETICAL FRAMEWORK

Page 13

Postmodernism

Page 14

Biopower

Page 15

CHAPTER FOUR: METHODOLOGY

Page 17

Foucauldian Discourse Analysis

Page 18

Social Media Research Ethics

Page 20

Data Collection \& Analysis

Page 22

CHAPTER FIVE: FINDINGS \& ANALYSIS

Page 22

Technology as Discursive Tools

Page 25

Depoliticizing Resistance

Page 32

Commodified Citizenship

Page 36

Body Positivity as Body Management

Page 39

Discussion

Page 45

CHAPTER SIX: IMPLICATIONS \& CONCLUSION

Page 49

REFERENCE LIST

Page 54 


\section{INTRODUCTION}

Weight stigma has a well-documented stronghold in North America, with discrimination based on size recorded in key areas of living, including education, employment, and healthcare. The most overt expression of anti-fat discourse, however, is in Western media where thinness is cemented as the culturally hegemonic standard of beauty. Media images are often found to contain messages glorifying thin ideals, as well as the promotion of dietary restraint and exercise regimens to manage the body. This movement contributes to a growing momentum to reject narrowly defined and inaccessible body ideals in favour of a more inclusive and positive conceptualization of body image. Popularized on social media platforms, body positivity promotes acceptance of bodies of all shapes, sizes, and appearances.

With its increasing popularity online, the body positivity movement developed new value in digital markets as global economies shifted from brick and mortar commerce to online retail spaces. What some experts identified as a delayed consequence of the Great Recession, the transition from traditional marketing to e-commerce demonstrated a profound shift in Western capitalism. As online shopping habits birthed new online marketplaces, communication technology supported its growth in the form of social media and influencer capital. As social media platforms shifted to include advertising and consumer options, body positive advocates and messaging began to include a neoliberal ideology.

Through Foucauldian Discourse Analysis, this research analyzes the impact of Instagram's transition to an advertising platform on the self-representation by body positive advocates. The performance of this corporeal discipline online by body positive advocates brings forth issues of representation, power, and neoliberal individualism. The current body of literature 
demonstrates a limited understanding of fat activism and the role body positivity plays. Research examining body positivity is necessary to further develop our understanding of emerging social and cultural influences that may be contributing to the shifting fat activism landscape.

As body positivity cements itself as a subculture of fat activism, the question of performing this embodiment online compels discussion on contemporary social movement strategies, consumer activism, and digimodernism. Social media has become an important site to contest prescriptive forms of embodiment, often through transgressive and re-articulations of difference, presenting critical opportunities for research. While social work research has historically shied away from discussions of technology, as a professional field of practice focused on interpersonal human contact, it is ideally positioned to deal with the questionable onslaught of technological and corporate influence in human affairs.

Thus far, academic literature has applauded the democratic potential of social media to facilitate egalitarian spaces for marginalized groups and undermine traditional power structures; failing to question the role communication technology plays in the construction and reconstruction of social movements. Social work has always been defined by its relationship with social justice, it often being the element that separates the field from other helping professions. As one of the most overt examples of corporate co-option, body positivity research is essential to further our understanding of the role communication technology plays in contemporary resistance movements and online support networks. As body positivity becomes further entrenched online, social workers must recognize the role it plays in the offline experiences of vulnerable individuals and communities. 


\section{LITERATURE REVIEW}

Many describe themselves as body positive, but few can agree on a shared definition of the term, much less a rubric for what qualifies as body positive. Fat activism as a general subject continues to be a marginal study even within fat studies (Cooper, 2016). While the scholarship of fat studies has produced a whole field dedicated to fat embodiment, it continues to be limited in its scope of fat activism, producing little on the topic of body positivity. Of the literature that exists, four major themes were identified, a) the neoliberal construction of fatness, b) consumer activism, c) the history of the fat acceptance movement, and d) contemporary body positivity and social media. Unfortunately, these themes are representative of both the gaps and problematic realities of fat activism literature. These themes reflect what Cooper (2016) characterizes as 'proxies' that exist in fat activism research, arguing that these proxies predominate because research into fat activism is currently limited, affecting the kinds of knowledge that exist.

\section{Neoliberal Construction of Fatness}

In this modern age, the healthy body has come to signify the morally worthy citizen, one who exercises discipline over their body, extending the reach of the state, and willingly sharing the burden of governance. While the nomenclature of the 'obesity epidemic' is a relatively recent phenomenon, academic literature has demonstrated the harmful impacts of such anti-fat discourse on individual mental wellness (Cohen, Fardouly, Newton-John, \& Slater, 2019a; Cohen, Irwin, Newton-John, \& Slater, 2019b; Matacin \& Simone, 2019; Webb, Vinoski, Bonar, Davies, \& Etzel, 2017; Webb, Thomas, Rogers, Clark, Hartsell, \& Putz, 2019) as well as larger systems of governance (Elliot, 2007; LeBesco, 2011). The figurative concept of citizen fitness 
has been mistakenly conflated with the aesthetics of thinness. Active and working bodies are thought to be positive contributors to democracy, while the opposite are drains and detriments on an already burdened system.

Such a shift in thinking about fatness is accompanied with the move to a neoliberal form of government described by Michel Foucault. While neoliberalism has many shifting definitions as its relates to both policy and ideology, in this context neoliberalism is defined as a political and economic rationality characterized by privatization and deregulation; alongside an emphasis that human wellbeing can be advanced by liberating individual entrepreneurial freedoms and skills within an institutional framework characterized by strong property rights, free markets, and free trade (Elias \& Gill, 2018). Individuals are constituted as self-managing, autonomous, and responsibilized. Where there is no safety net, people face greater pressure to be fit for the marketplace, to present themselves as competitively employable.

When considering the role of embodiment, fat people represent failed citizens within a neoliberal ideology: "the slow, unwell, undisciplined, and unemployable losers in the race of life whose only chance at betterment is participating in neoliberal regimes" (Cooper, 2016). The theories and concepts of Foucault position society as normalizing certain bodies, making them docile, obedient subjects that "voluntarily agree to approximate these norms under a gaze that keeps deviance under strict surveillance" (LeBesco, 2011). Specifically, as it relates to health, fat bodies are reframed as a burden on an overworked healthcare system due to poor personal consumption choices. Cain, Donaghue and Ditchburn (2017) clearly identified this pattern in traditional news media. These 'irresponsible individuals' demonstrate the "enmeshment of obesity discourse within the broader cultural logics of neoliberalism, and the difficulty of thinking outside individualistic frames of meaning and accountability" (Cain et al., 2017). 
Citizens are increasingly expected to play an active role in minimizing their contribution to healthcare costs by becoming more responsible healthcare 'consumers' and adopt appropriate practices of prevention (LeBesco, 2011).

While this discourse of failed citizenship is a demonstrated characteristic of anti-fat discourse found in both traditional (Cain et al., 2017) and new media (Webb et al., 2019), body positivity was also found to engage in neoliberal ideology despite its commitment to resisting the same systems that had marginalized them. Minor turns in this literature are reflected in fatshion and beauty (Gurrieri \& Cherrier, 2013; Scaraboto \& Fischer, 2013), health and fitness (Webb et al., 2017; Webb et al., 2019) and self-care (Bombak, Meadows, \& Billette, 2019; Cain et al., 2017).

\section{Consumer Activism}

The exercise of an individual's freedom to engage in commodity consumption is closely connected with contemporary neoliberalism. In North America, citizenship and the ability to participate in the public sphere is contingent on the extent to which individuals can participate in consumer culture. As citizens of a capitalist democracy, one's primary function is to consume. Elliot (2007) emphasizes that, in recent years, "the site of citizens' political involvement is moving from the production side of the economy to the consumption side."

Fashion and beauty industries have an especially prominent history of excluding fat bodies, limiting their ability to participate in consumer culture. Body positivity advocates have argued for increased access to these markets in order to leverage their consumer citizenship. These conflicts are often fought in the 'fatosphere', a virtual space containing an online network where fat activists attempt to renegotiate boundaries of fat embodiment, citizenship, and neoliberal 
forms of self-subjectification (Adwoa \& Ricciardelli, 2015). The fatosphere is a central spot of academic study, which has demonstrated its capacity as a shared community where activists reframe public citizenship to help renegotiate its terms so fat people can experience market privileges (Adwoa \& Ricciardelli, 2015; Dickins, Browning, Feldman, \& Thomas, 2016; Gurrieri \& Cherrier, 2013).

One central way advocates redefine consumer citizenship is through 'fatshion'. 'Fatshionistas' are fat women who disrupt normalized understandings of beauty and its social categories via active participation in fields of beauty (Gurrieri \& Cherrier, 2013). Fatshionistas is a popular category on social media platforms given its goal of gaining visibility to challenge stereotypes that fat cannot be fashionable or attractive. Gurrieri and Cherrier (2013) demonstrate a variety of visibility tools by fatshionistas, including a 'coming out' process whereby the online persona is established through hypervisible participation in beauty culture as a fat person. Similarly, Adwoa and Ricciardelli (2015) found visibility to be a common theme in their research on body image and beauty standards. Selfies were a strategic tool whereby fat women constructed fat activism as consumerist practices, modeling and styling clothing to normalize fat bodies and counter reductive narratives around fatness. In this way, fatshionistas model a neoliberal version of fat activism where fat women are able to support each other through consumerist practices while creating the opportunity for larger women to 'come out' as fat by playing with symbols of beauty.

Fatshionistas frequently mobilized others to form a community, interacting in both virtual and physical space to form a 'fat citizenship' that disrupts thin normativity. This fat citizenship is gained through recognition in traditional markets. Fatshionistas consistently indicated that mainstream markets provided them with limited fashionable clothing options, curbing their 
'right' to consumer choices that is enshrined by law in many market-based economies (Saraboto \& Fischer, 2013). Many argued that, given the importance of aesthetics for women in terms of employability, the lack of clothing or beauty options is detrimental to their socio-economic mobility. The body of literature found that political consumerism and conscious consumerism were frequent and effective tools of the fatshionista community (Adwoa \& Ricciardelli, 2015; Bombak et al., 2019; Gurrieri \& Cherrier, 2013; Scaraboto \& Fischer, 2013; Webb et al., 2017). Leveraging their purchasing power, fatshionistas were able to provide a platform for producers and consumers to bring out systemic change; achieving extended clothing sizes, advocating for body diversity in modelling hires, and dispersing power amongst fat retailers.

While free market ideals retain a canonical presence in contemporary culture, progressive social ideas have been readily incorporated into capitalist marketing and promotional campaigns. This 'commodification of dissent' has been argued by many to constitute a key feature of contemporary neoliberal culture (Bombak et al., 2019; Cwynar-Horta, 2016; Sastre, 2014; Taylor, Johnston, \& Whitehead, 2016). As body positivity continues to grow as a commodified value, an internal debate has flourished whereby members of the body positivity community question the shape the movement has taken in recent years. While initially concerned with eliminating the structural barriers created by institutionalized fatphobia, body positivity seems to have abandoned larger sized women, rendering them invisible in a movement originally meant to represent them. Community members have critiqued body positivity for failing to be inclusive of all identities as the movement has come to represent conventionally attractive, thin(ner) white women who are being positive about their bodies. Former leaders of the movement have been seen to abandon body positivity, disappointed with its appropriated use of radical spaces for assimilationist goals. A stark example of this can be found in fatshion's origins. Coined by 
Amanda Piasecki in 2004, fatshion was initially a product of the queer femme community where "adornment was a means of survival and visibility, and where people came from traditions of using whatever resources were available to them" (Cooper, 2016). But as fatshion quickly grew beyond small community discussions, Piasecki became its loudest critic, citing consumer citizenship within fat activism and fashion: "This kind of consumer citizenship that is centered around fashion...I think has a daily assimilatory tendency to it" (cited in Cooper 2016). What started as a form of resistance and critique by people with limited capital to participate in neoliberal culture is now a buying opportunity which further excludes those too poor to participate. What was once a community discussion about fat, fashion, and politics for working class people, queers, and people of colour, has been 'gentrified' into a powerful tool of digital consumerism.

While body positivity is still a new subject of academic research, scholars in the fields of sociology (Bombak et al., 2019; Taylor et al., 2019), media studies (Sastre, 2014), and fat studies (Cain et al., 2017; Rothblum, Solovay, \& Gingras, 2009) have explored the concern and critique of community members over the commercialization of the social movement. Bombak, Meadows, and Billette (2019) interviewed a primarily homogenous sample of white, midwestern American women on their perspectives on cultural body acceptance; revealing the blend of positive and negative perspectives on the body positivity movement. As 'hip consumerism' dominates younger generations' relationship to consumer culture, Taylor, Johnston, and Whitehead (2016) explored feminist' perspectives on such advertisements as the Dove Real Beauty campaign as they engage with a postfeminist reality. Finally, as the body positivity movement gains momentum, Sastre (2014) performed a discourse analysis of various body positive websites to interrogate the ways in which these sites facilitate an enactment of body positive tenants. While 
each study acknowledged the contribution body positive spaces had made in the way of increased representation and access, the movement was characterized as 'lip service' with increased skepticism; citing the escalating "institutionalized, corporatized, and social media pushes for greater diversity" (Bombak et al., 2019). Participants were suspicious of advocates' ultimate motivations as countercultural resistance to conformity successfully and productively merged with entrepreneurial culture.

\section{The History of the Fat Acceptance Movement}

Body positivity is often described as 'rooted' in fat acceptance, specifically in North American movements like the National Association to Aid Fat Americans (NAAFA) and the Fat Underground (FU). The National Association to Aid Fat Americans began with Llewellyn Louderback, a writer and journalist who published an article advocating for the respect and rights of fat people. Having read and been inspired by the article, William Fabrey, a normatively-sized engineer and self-identified 'fat admirer' contacted Louderback asking for permission to distribute reprints of the article. Louderback later issued a call to action on behalf of his and Fabrey's wives, two fat women, convening an assembly to approve a formal constitution and bylaws for NAAFA in 1969 (Lupton, 2018). NAAFA became an important source of community building and interpersonal support for fat people. Further, Louderback was one of the first activists who argued that fat hatred was ingrained in dominant media, medical, fashion, and weight loss discourses (Cooper, 2016). His publication, Fat Power called for readers to resist and critique these harmful narratives.

While often celebrated as a blueprint for modern fat activism, NAAFA was conceived as an organization by normatively-sized men with a sexual desire for fat women who were 
interested in developing activism that benefited them as well as their sexual and romantic partners: "I want to make the world a safer and more pleasant place for persons of size, and for them to like themselves better, and lastly, and less important, for nobody to tell me what my taste should be" (cited in Cooper, 2016). Given the issues present in NAAFA, alternative movements were founded, including the Fat Underground. Judy Freespirit and Sara Alderbaran were original NAAFA members who divested from the group to create an organization more in line with their radical feminist values (Smith, 2019). Freespirit and Alderbaran were critical of the medicalization and depoliticization of ordinary human experiences and oppression. Their approaches to fat activism was in stark contrast to NAAFA: "The Fat Underground confronts the double oppression of fat women in society through our nutritional, psychological, and politically radical analysis of our condition which disputes all present myths about fat" (cited in Cooper, 2016). The Fat Underground aligned themselves with other civil rights movements at the time, focusing on direct social actions to challenge anti-fat discourse and inspire consciousness-raising to resist American diet culture (Smith, 2019).

While both the National Association to Aid Fat Americans and the Fat Underground both helped to develop contemporary fat activism, Cooper (2016) cautions against such limited understandings of fat activism where Western agendas are reproduced as the only legitimate style of fat activism. She argues that the predominant focus on NAAFA by researchers has developed a minor proxy whereby fat activism is constructed to be primarily concerned with stigma and changing negative cultural assumptions of fatness. This is seen in body image literature (Adwoa \& Ricciardelli, 2015; Cohen et al., 2019b; Webb et al., 2017; Webb et al., 2019) and is reflected in the body positive movement where anti-fat stereotyping is overcome through visibility efforts. 


\section{Contemporary Body Positivity and Social Media}

Social media networking sites have become one of the most dominant and influential mediums to cultivate awareness, foster community, and advocate for social change at a global level. Compared to traditional media, the sharing ethos of social media allows marginalized bodies to create and curate their own content, taking up space where previously they were excluded by dominant appearance standards (Lupton, 2017). New communication technologies have fostered a participatory democracy that offers body positive advocates the opportunity to engage with new media, becoming co-creators of content.

In particular, body positivity has become popularized through photo-based social networking sites, like Instagram which has seen a significant increase in body positive content. Body positive advocates proudly showcase images featuring uplifting affirmations and celebrating attributes incongruent with societal beauty ideals, including cellulite, stomach rolls, and stretch marks. Instagram offers body positive advocates a global platform to reframe the prevailing discourses on body image, beauty standards, and health to be more inclusive. Body positive accounts on Instagram provide a "unique perspective in an otherwise perfectly manicured environment for users to view bodies much like their own with natural lumps, bumps, and curves that are displayed openly" (Cohen et al., 2019b).

This democratic approach to social media has been troubled in recent years, as social media has become an important advertising vehicle for brands looking to reach consumers in a new digital economy. The commodification of users on Instagram follows its transition to an advertising platform in 2013 (Cwynar-Horta, 2016). While social media profiles function as a 'site of becoming' for users as they create their virtual presence, corporations became aware of 
their commercial value and began capitalizing off the labour of users. Instagram currently boasts 600 million active users, classifying it as one of the most popular social media platforms for influencer marketing (Bratu, 2019). Influencer marketing is the identification and use of specific key individuals who hold influence over potential buyers to aid in the marketing activities of a brand (Evans, Phua, Lim, \& Jun, 2017). Due to its ability to reach a large segment of consumers in a short period of time, and its low cost compared to traditional advertising strategies, influencer marketing has emerged as a highly popular way for brands to engage consumers online (Bratu, 2019).

Adult social media users have demonstrated positive attitudes towards influencers, citing their honesty, knowledge, authenticity, relatability, and transparency (Bratu, 2019; Evans et al., 2017; Khamis, Ang, \& Willing, 2017). The ideal traits of a human brand - authenticity, relatability, and transparency - perfectly overlap with body positive ideology where advocates authentically bare their bodies and experiences, making them natural and valuable assets in this new digital economy. Brands collaborate with influencers through sharing sponsored content, product placements, documenting a sponsored event or experience, hosting promotional events, and event appearances. Influencers have been shown to favourably shape product awareness, positively influencing consumer behaviour (Bratu, 2019). As the digital economy bypasses its traditional counterparts, the commercial value of body positivity has increased with their online presence shifting to include a consumer element.

Commercial opportunities made available by Instagram's advertising structure has given rise to an increase in self-branding among body positive advocates, drawing criticism from community members concerned with the overall direction of the movement. As advocates engaged in brand partnerships with plus-size clothing brands and promote their accessible 
clothing 'hauls', critics argue the movement is more associated with consumer activism than radical social change. Sastre (2014) characterizes body positivity as a collection of "body oriented initiatives in a neoliberal matrix of consumption-driven self-actualization." As a tool of activism, capitalism has shifted the goal of body positivity to access rather than social transformation.

In North America, citizenship and the ability to participate in the public sphere is contingent on the extent to which individuals can participate in consumer culture. Body positive advocates often seek to better engage with consumer markets through mobilizing fat citizenship, advocating for clothing size accessibility and body diversity in brand campaigns (Gurrieri \& Cherrier, 2013). Critics often define this kind of political consumerism as assimilation where fat people are embraced as "consuming subjects but not as social subjects" (Cooper, 2016). The exercise of an individual's freedom to engage in commodity consumption has been connected with contemporary neoliberalism which emerged as the hegemonic political, economic, and social policy of the West in the 20th century.

\section{THEORETICAL FRAMEWORK}

Since it is designed for public consumption, the 'branded self' seamlessly plays to postmodern notions of identity. Additionally, the influence of neoliberal and capitalist ideology on body positive advocates' self-representation calls into question concepts of power, embodiment, and discourse, making postmodernism an ideal paradigm from which to approach this research. Traditionally, postmodernism has been defined in opposition to modernity, suggesting an "epochal shift or break from modernity involving the emergence of a new social 
totality with its own distinct organizing principles" (Featherstone, 2007). Postmodernism frequently stresses the influence of new forms of technology and information in a movement towards a post-industrial age. In the context of social work, postmodernism offers researchers and practitioners the opportunity to "explore concepts of practice that defy categories based on level of practice" (Moffatt, 2019). These concepts include the self, power, discourse, subjectivity, and affect that are both individual and social in nature.

In our modern world, technology is central to contemporary communication and the construction of social relationships. These relationships are increasingly imagined through and constrained by technological forms of communication (Moffatt, 2019). Social media, in particular, is driven by a specific identity construction where users create a highly curated and often abridged snapshot of themselves. Social media as a unique form of digital communication has supported the proliferation of the branded self, providing for global interaction, and commercial communication (Khamis et al., 2017). Structural transformations associated with neoliberal ideologies of individuality and self-governance have instigated more calculated strategies to brand the self. Traditional markets have shifted to a gig economy where, combined with a weakening social safety net, self-management is the norm. With dwindling opportunities for traditional and secure employment, marginalized individuals look to alternative forms of income. This new economic expectation harmonizes with neoliberal values of individual efficacy and responsibility, resting on capitalistic faith in enterprising, resourceful, and self-directed labour.

Global capitalism coupled with communication technologies like social media has wrought significant cultural, economic, and political upheaval. Marketing and media scholars (Duffy \& Hund, 2015; Evans et al., 2017) have proposed that the concept of self-branding 
manifests as an "apposite navigation strategy for otherwise vulnerable and overwhelmed individuals" (Khamis et al., 2017). Academics have characterized the new media work environment as one wherein traditional power hierarchies are supplanted by a new workersubject tasked with managing the self in conditions of radical uncertainty. This mode of selfgovernance shifts the burden of management from formal corporate structures and welfare bodies onto the individual, testifying to the encroachment of commercial discourses in all realms of social life.

For the purpose of this research, postmodernism is situated within the realm of Michel Foucault through the concept of 'biopower'. Foucault's (1990) work on the disciplined body as a tool of the state was pivotal in opening up a new set of understandings about the nature of the 'body as message'. The Foucauldian body is self-disciplined and therefore becomes an object on which power is both visibly and invisibly rendered. It is the related technologies developed to facilitate this regulation that mark the beginning of an era of biopower. Biopower refers to the practice of the state and its regulation of its subjects through "an explosion of numerous and diverse techniques for achieving the subjugations of bodies and the control of populations" (Foucault, 1990).

Within the realm of obesity discourse, academic scholarship has intimately investigated the role biopolitics plays in the medicalization and management of fat bodies. Elliot (2007) demonstrates how citizen fitness became defined through the lens of physical health during the Second World War. With the development of Canada's first official food guide in 1942, the state listed a range of 'healthy' foods to create a better army, aligning dietary choices with nationalism: "Canada at war cannot afford to ignore the power that is obtainable by eating the right foods" (Elliot, 2007). Popularizing the 'war on obesity' is evidence of the twentieth- 
century trend towards medicalizing ailments previously seen as the result of moral failings. The major technological shift in medical politics comes with the reliance of practitioners on the Body Mass Index (BMI) scale. Despite its lack of scientific rigor, as a mechanism of biopower, the BMI scale is a common technique of control to discipline fat bodies (Evans \& Colls, 2009; Friedman, 2012). In the context of fatness discourse, Cook and Wilson (2019) define biopower as the subjugation of bodies for the purpose of controlling populations to ensure the success of capitalism.

Postmodernism warns against "misguided attempts to find a single, unitary, and foundational explanation in the social and economic context of capitalism and neoliberalism" (Moffatt, 2019). Given the failure of academic research thus far to critically interrogate the body positivity movement, choosing to instead unilaterally celebrate it as a positive shift in body image work; postmodernism's commitment to embracing the inconsistencies and contradictions inherent in discourse can act as a guiding principle. The goal of this research is not to replace one objective truth with another, but to expose the variety of truths at play and the mechanisms by which they came to power. While many aspects of the body positivity movement have been depoliticized in favour of an individualistic approach to self-love, Foucault reminds us that practices of the self are not invented by the subject's themselves, but rather as "proposed, suggested, and imposed" on them by one's culture, society, and social group (LeBesco, 2011). The self is a phenomenon that is imagined and reimagined through a matrix of discourse, knowledge, power, and relationships (Moffatt, 2019).

This research is concerned with representations of the self as they relate to neoliberal culture. Kristeva argues that the effect of contemporary capitalist culture is redefining the nature of the social bond, and what it means to be human (cited in Moffatt, 2019). Since the self is 
constructed in relation to this social reality, new forms are created within the commercial context of capitalist settings. Kristeva argues that a consumerist approach to symbol creation results in a narrowed space to explore meaning, putting ourselves at risk of understanding ourselves through a limited discourse of commerce (cited in Moffatt, 2019). It is proposed that neoliberal influence has resulted in a commodification of social media platforms, influencing the self-representation of body positive advocates.

\section{METHODOLOGY}

Postmodernism frequently mobilizes concepts of power to critically examine the ways in which our practices contribute to the surveillance and discipline of one another. These concepts regularly lead to a critical analysis of discourse. Karen Healy defines discourse as language practices through which knowledge, truth, the self, and social relations are constructed (cited in Moffatt, 2019). Particular attention is given by postmodernists to opening up alternative discourses to encourage moving away from essentialist approaches to understanding. Body positivity has been constructed by both mainstream and academic bodies as an individualistic counterdiscourse with very little critique. Discourse analysis offers the opportunity to deconstruct said categorical thinking and reconstruct new discourses, practices, and processes. Unlike other research methodologies, critical discourse analysis explores the relationship between text, discursive practices, and historical events, as well as wider social structures (Moffatt, Panitch, Parada, Todd, Barnoff, \& Aslett, 2016). A specific set of factors have converged to problematize body positivity, including the domination of neoliberal ideology and structures, the development of sophisticated communication technology, and resistance strategies 
of the fat activism movement. It is in this critical landscape that this research is located. Critical discourse analysis interrogates discursive events to uncover the political assumptions through which these agendas have come into being (Moffatt et al., 2016). Given the historical analysis inherent to its methodology, Foucauldian Discourse Analysis (FDA) is an ideal choice in exploring how narratives unfold in social media spaces.

Foucauldian Discourse Analysis builds its foundations from the writings and concepts of Michel Foucault. This research aims to understand how biopower operates through discourse, and how this manifests within self-representation practices of body positive advocates online. Foucault (1984) defined discourse as a collective 'social practice' rather than an individual practice. Foucauldian conceptualization of discourse differs from traditional approaches in a few key ways, making it an ideal methodology for this research. As a 'top down' perspective, Foucauldian Discourse Analysis focuses on broader, ideological and social issues as they relate to power and knowledge through discourse. Being inherently political in orientation, Foucauldian discourse allows for a greater understanding of the body positive movement by first defining said problem and then critiquing and questioning the legitimacy of established assumptions, structures, and social dynamics related to the issue. Secondly, the Foucauldian understanding of discourse as autonomous and independent from human agency allows opportunity to study the larger impact of body positivity. Frequently characterized as an interpersonal approach to body acceptance, body positivity has avoided politicization through its association with the self-help movement. This structural analysis gives discourse agency through the construction of objects. Investigation into the self-representation of body positive advocates through a Foucauldian lens will establish "the rules of what can or cannot be said" (Sam, 2019). 
The application of Foucauldian Discourse Analysis is less linear and more iterative due to its interpretive process. For that reason, the positionality of the researcher plays an important role where ontology and epistemology are functionally one in the same (Sam, 2019). As both a researcher and consumer of body positive content, it is essential to understand that one's position in the world is not separate from one's understanding of it. This process of situating oneself is incredibly important in the process of enacting Foucauldian Discourse Analysis so as to avoid the methodology becoming "mechanized and instrumental and reduced to methods, process, and critique" (Sam, 2019).

The application of Foucauldian discourse is not fully agreed upon in the literature, with various authors offering 'flexible guidelines' (Arribas-Allyon \& Walkerdine, 2008; Kendall \& Wickham, 2009; Willig, 2001). For this purpose, the work of Arribas-Allyon and Walkerdine (2008) will act as a methodological guide. They suggest starting with problematization or the defining of a problem that arises when different discourses intersect and power-knowledge relationships are exposed. This first step was previously accomplished whereby critical factors were identified as antecedents of modern body positivity. Data collection is then conducted through a selection of 'statements' predicated on Foucault's definition which is a special mode of existence. A corpus of statements must provide enough examples and variation for analysis (Arribas-Allyon \& Walkerdine, 2008).

The data landscape will be situated in social media platforms, specifically Instagram. Though the body positive community has online and offline manifestations, its online form was chosen due to its archive of ideological, discursive, and visual practices. As social media cements itself as one of the most dominant and influential mediums in contemporary society, researchers should consider it a viable and important site for research. As social media becomes 
a more plentiful site for research, however, new and rigorous guidelines need to be developed and adhered to. While qualitative research has quickly adapted to using social media for participant recruitment and dissemination of findings, this research will locate its data and analysis in social media postings from public and verified Instagram accounts to the development and impact of its discursive practices. Such methodologies and data content are currently limited in social work research, leaving little guidance for research ethics.

Ryerson University (2017) echoes an industry standard, locating the majority of its social media research guidelines in recruitment strategies, dissemination projects, and observational research. While researchers warn of making assumptions about intellectual property rights due to the public nature of social media, little thought is given to other potential risks and considerations. The mass growth of visual-heavy social media platforms, like Instagram has contributed to a rise in habitual sharing of images, and specifically of the body, online. Given the research focus on body positive Instagram accounts, which are characterized by increased visibility of marginalized bodies in public spaces, digital ethics are further problematized by the subject of said content. While a significant amount of research has been produced in terrains of internet research ethics, little work has been published on the specific digital ethics of researching images of the body on digital communication platforms (Warfield, Hoholuk, Vincent, \& Dias Camargo, 2019). The little research that currently exists represents a dialogical debate in which two camps of research ethics currently exist.

In line with the legal precedent of intellectual property rights, one camp is aligned with user agreements and motivated by capital and sociality, believing that online data must be defined as 'public' in order to promote dissemination and data inquiry. Social media user agreements often state that data shared is public, with the platform encouraging sharing, re- 
sharing, blogging, re-blogging, posting, and re-posting, compelling transparency to the data shared online. Further, as it pertains to university research ethics boards, certain modes of online data are often exempt from ethics approval because it was determined that the publishers of said data have already relinquished their privacy rights as a consequence of their participation in online sharing platforms (Warfield et al., 2019). The second camp is motivated by fierce ethics of care, pushing for a more nuanced characterization of data as bodily and materially connected to the image-makers.

As such, the literature offers two ethical approaches, feminist ethics of care, and contextual integrity (Warfield et al., 2019). A key ethical framework in digital ethics, feminist ethics of care emphasizes relationality, mutual care, and respect between participant(s) and researcher (Markfield \& Buchanan, 2018; Warfield et al., 2019). Contextual integrity calls for ethical decision-making through the application of "practical judgement attentive to the specific context" (Markfield \& Buchanan, 2018). Both these approaches converge into feminist materialist ethics of care (Hendersen, Johnson, \& Auld, 2013) in which this research locates its own approach to ethics.

Feminist materialist ethics of care attends to the digital bodily assemblage, which includes both human and non-human entities - the material body, the digital data double, the data traces left online, and the manner in which platform affordances may act to shape digital subjectivities (Warfield et al., 2019). In practice, this is the application of a personal and reflexive algorithm of decision-making around images in context. This process will consider all the socio-technical factors that come into play in maintaining the contextual integrity for imagemakers. Questions that may be asked during this process could include: Is using the photo necessary? Is including the body necessary? If it is, are there opportunities to mask or modify it? 
While there are no plans to disseminate this research past a university platform, the definition of consent used in this research process acknowledges the diversity of publics that exists on different platforms (Warfield et al., 2019), demonstrating that "ethical decision-making is best approached through the application of practical judgement attentive to the specific context" (Markfield \& Buchanan, 2018).

By locating the research in the digital landscape of social media, an environment with a never-ending torrent of material information is now available. Given the overabundance of data, Sam (2019) advises to take small samples over time to capture some of the discourse. The selected corpus of statements was chosen according to theoretical sampling whereby fifteen 'posts' were chosen according to its demonstrating an element of biopower.

While Instagram is an image-based platform, it offers multimedia opportunities for analysis, including visual pictures and video, textual captions, and symbolic hashtags. For the purpose of this research, all three elements will be analyzed. Fifteen posts were chosen over the course of three months to make up the corpus of statements. Data analysis was conducted by reading through and visually comparing various posts, clustering different examples of biopower within the corpus based on cases of self-representation. Secondly, the Instagram search engine and snowball sampling were used to find additional posts to reflect the cluster. Finally, posts were reordered and examined for differences and similarities, both within and between the clusters.

\section{FINDINGS \& ANALYSIS}

In the current era of accelerated globalization and new communication technologies, constellations of alternative discourses proliferate and acquire meaning in the visual regimes of 
networked social media. While the origins of the internet were characterized by hopeful promises of a democratic free space enabled through decentralized networks of emerging technologies, contemporary understandings of communication technology have revealed digital participatory culture to be nothing more than smoke and mirrors. The implied opposition between passive recipients defined by traditional media and active participants inhabiting digital environments is a historical fallacy. Body positive advocates are operating in a media environment that held promise of being more egalitarian, one in which it was presumed that a new politics of meaning would undermine and replace long-standing power relations. While the user-directed structure of social media platforms has dented the hierarchical structure typical of traditional media, body positive influencers mostly replicate the homogenizing logic of mainstream media.

The defining feature of digital media is that users have better access to networked media, enabling them to 'talk back' in the same multi-modal language that frames cultural products formerly reserved for old media content creators. Made possible through the availability of cheap and accessible technologies, digital participants are ascribed a heightened level of engagement with society, enhancing a new cultural citizenship. At the same time, individuals are increasingly dependent on those same digital platforms to provide them the means for the construction of their life projects. This double-bind of media dependency evokes the influence of soft power technologies necessary for biopolitical governance.

The current trend of participation culture emphasizes users' strong preference to share knowledge and culture in communities. Sharing has become the default mode of most social networking platforms. These digital communities strongly denote the inclination of users to belong to a group and be involved in a common cause. As generations defined by their early use of technology engage in activism, the internet becomes an expected site of social resistance. The 
internet was envisioned as a new frontier space where grassroots initiatives and 'free' amateur culture had a chance to bloom. Body positivity sits at this unique intersection of online activism and digital entrepreneurship. Technology has always existed as a vehicle for neoliberal capitalism to travel, as evidenced by the rapid spread of globalization. The digital domain is a convenient pretense for the mobilization of 'immaterial labour' by body positive influencers, befitting the familiar logic of capitalist exploitation. As social movements increasingly engage in online activism, these research findings will demonstrate important implications for the 'commodification of dissent' and its impact on contemporary social movements.

The data assemblage reflects the primary force of body positivity as commercial, where the disciplined regulation of the body is facilitated by the purchase of goods and services, and through these transactions proper citizenship is enacted. Four themes were identified, having demonstrated the influence of biopower to regulate bodies deemed 'at risk' to state control. These themes include a) technology as discursive tools, b) depoliticizing resistance, c) commodified citizenship, and d) body positivity as body management. First, the innate architecture of Instagram as a social media platform was seen to influence the self-representation of body positive advocates. Second, body positivity encourages a solipsistic focus on the self, effectively mandating an apolitical engagement in body positive spaces. Third, the focus on selfbranding by body positive advocates has resulted in a self-representation created within the commercial context of capitalist settings. Finally, body positivity has been mobilized to craft and legitimate race, embodiment, and beauty hierarchies that remediates neoliberal rhetoric and ideology. As a whole, the findings demonstrate an intimate link between self-representation of body positive identities and consumer capitalist culture. 


\section{Technology as Discursive Tools}

With the radical increase in digital communication technologies, social media sites not only provide new opportunities for social interaction but also afford new opportunities for selfrepresentation. Just as physical settings inform traditional interpersonal interactions, online spaces encourage and discourage certain forms of identity and social exchange. With social interaction increasingly moving online, important questions emerge about the ways in which the self is structured by the architecture of online spaces.

Instagram is a social networking platform designed to share photos and videos from a mobile device. Whereas other social media platforms focus on text-based communication, Instagram's primary mode of communication is visual imagery. The platform is configured around the contemporary, with the application designed to document moments in real time. Instagram's founders describe the company as a "global community" (cited by Baker \& Walsh, 2018) that captures and shares the world's moments, demonstrating the platform's capabilities to allow user content to be produced, disseminated, and consumed immediately. The immediacy of Instagram's design lends user content a quality of authenticity, implying a tangible connection to users' offline lives.

This narrative of authenticity, in which an influencer's online presentation is presumably cohered with their offline self implies a quality of trustworthiness. Body positivity advocates actively engage this feature of the platform, baring the self and the body, including all of its purported flaws. Body positivity frequently blends this narrative of authenticity with hypervisibility, regularly posting content of the exhibited body. Images regularly feature advocates in little to no clothing, the message being that the body no longer needs to be buried 
beneath layers of clothing meant to 'flatter' or conceal. Advocates are exposed to a viewing public in defiance of the social pressures that once kept them hidden.

In an effort to enact authentic representation for a spectrum of body types, body positive advocates willingly submit to the digital surveillance required of neoliberal citizenship. This surveillance is built into the architecture of Instagram's platform. Based on an expectation of immediacy, Instagram requires influencers to immerse their followers in every aspect of their lives, capturing and posting mealtimes, exercise routines, social activities, and self-care techniques. This daily surveillance acts as a biometric form of monitoring, creating a 'quantified self' who uses the affordances of digital technology to collect, monitor, record, and share a range of quantifiable and non-quantifiable information about themselves; while engaging in the process of making sense of this information as part of the ethical project of selfhood (Elias \& Gill, 2018). This biometric form of monitoring serves to regulate, define, and control populations to create new subjectivities through digital means. This kind of surveillance is incentivized by Instagram's monetized structure, making body positive influencers submit to such a posting schedule necessary to remain relevant and maintain their earning potential. In this way, body positive advocates are required to submit themselves to a lifetime of self-surveillance.

Instagram offers various tools from which users can edit, and experiment with, how they present themselves online. One such tool is the ability to cluster multiple photos and videos in a single post to create longer, more complex visual narratives. One photo, however, is chosen as the 'cover photo' which is shown on followers' news feeds and is advertised to potential new followers on their search feed. If interested, users can select the post to view the caption, hashtags, and additional visual content within the post. Of those body positive advocates that chose to use this cluster feature, many mobilized this device to disrupt the 'before and after' so 
often used in weight loss and diet culture discourses. Adhering to a discourse of overcoming, body positive advocates construct their thinner bodies as evidence of themselves 'before' they achieved self-love and body acceptance, which usually accompanied a weight gain typically demonized as a moral failure by diet culture discourses. Frequently associated with eating disorder recovery, Stephanie K. (@_classysurves_) used this feature to showcase her recovery journey, commenting that the first photograph represented "all the bad feelings and insecurities [she] had" while the last photograph represents an eight year journey to body acceptance, resulting in a more "confident and happy" person. While body positive advocates successfully disrupt the rhetoric of fat bodies as failed thin citizens, they continue to adhere to a discourse of overcoming and transformation typical in makeover and diet culture.

Similarly, body positive advocates often used this cluster feature to push back against the faux authenticity typical of mainstream fashion and beauty accounts. Posting photos that first mimic attractive qualities consistent with dominant beauty ideals, body positive advocates then include subsequent photos revealing that, under 'normal' circumstances, their bodies possess the same dimples, rolls, and cellulite as their followers. With a cluster of seven photos, Joey Darlin (@joeydarlinn) reminds followers that “NEWS FLASH - my belly rolls just like yours when I'm not posed don't forget that everyone here is normal too." Darlin's cover photo, however, shows the plus-size model reclining effortlessly in a flattering pose featuring a desired hourglass shape, flat stomach, and fashionable pout. Subsequent photos take on a 'behind the scenes' quality, where Darlin exposes her thicker waistline and belly rolls as she changes to a more natural pose sitting up on her hips. As body positive advocates call for their followers to reorient their bodily expectations, 'exposing' the realities of social media, other accounts echo Darlin, using language to promote a sense of normalcy and community, commenting that "everyone has cellulite" and 
that "softness is beautiful." While this could be viewed as an efficient tool from which to challenge the discourse of authenticity on Instagram, many body positive accounts purposefully conform to homogenous beauty standards; selecting a cover photo that closest resembles mainstream beauty ideals, ultimately reflecting, rather than rejecting, the very narratives of conformity and regulation they seek to change.

All content included in the corpus of statements feature the body as the focal point, demonstrating the hypervisibility so often found in body positive representations of embodiment. The bodily representations, however, continue to conform to hegemonic expectations of Western femininity, featuring an hourglass figure, a thin(ner) waistline, large breasts and hips, and Eurocentric facial features. The camera is often positioned according to 'selfie angles' at arm's length and adjusted downward to give a slimmer appearance and emphasize an acceptably feminine figure. Advocates are seen positioning their bodies to accentuate their hips and minimize their midsections, sometimes stretching their torsos to smooth out their waistlines. These adjustments, coupled with the intentional choice in featuring said images in the cover photo, directly contradicts body positivity's core messaging of challenging thin beauty ideals and celebrating body diversity.

This choice in cover photo demonstrates an understanding of what appeals to Instagram's larger audience. As with other social media platforms, Instagram employs a 'scroll culture' whereby influencers are required to compete for the attention of users flooded with an overabundance of content in their newsfeeds. In an environment of media surplus, where audiences are saturated with content, the premium on distinctiveness and visibility grows. To maintain their status, body positive advocates are seen mobilizing traits that are attractive and valued by those not yet abdicated from diet culture to attract new followers. Though these posts 
have the potential to act as a 'trojan horse', introducing new audiences to body positivity, the choice to lead with an image that maintains a hierarchy of beauty ideas where bodily 'imperfections' are regulated to a supplementary position in favour of a thin(ner) aesthetic reinforces the same system that body positivity claims to oppose. In this way, body positivity is both transgressive and assimilative.

Despite being a primarily pictorial medium, Instagram encourages users to represent themselves in the form of textual hashtags. This option is cultivated in the caption and comment sections which accompanies every post. Users adding hashtags to their posts make their content visible on a centralized page dedicated to a single hashtag. Hashtags are an effective way for the user to make content posts discoverable to public audiences, ensuring their content reaches beyond their current follower base. Instagram hashtags are therefore a way of organizing and categorizing content, creating an anthology of a particular discourse.

Thus, hashtags both collate content on Instagram while signifying community membership. Hashtag use designates the behaviour, verbiage, and discourse particular to the body positive community. Symbolic significance of hashtags for group membership was detected, as well as the degree to which self-representation was configured around platform interfaces. Body positive advocates were observed drawing on a common vocabulary to define their posts, and subsequently their self-representation. These textual references function as important signifiers, signaling a post's meaning and its connection to the larger community. Outside of taste network hashtags like \#bodypositive, \#bopo, or \#bodypositivity, a range of hashtags were identified to have useful benefits in cultivating different user groups, allowing advocates to construct their content, and their own self-representation, to attract new audiences. 
Branded hashtags were identified early in the data assemblage, where body positive advocates used brand names or slogans to promote products, or accompany advertising campaigns. Some examples included the promotion of clothing companies, like \#fabletics, or workout supplements like \#hiballenergyseltzer. While paid promotions and sponsorships were easily identifiable through the use of disclosure hashtags, such as \#ad or \#sponsored, other forms of commodification were less overt. Advocates often immersed these brand hashtags into their daily posts, retaining their identity as an honest and authentic role model while leveraging their online presence for economic gain: "This is what health + happiness look like...this \#premierretreat was absolutely incredible." In cases where advocates directly acknowledged the sponsored nature of their posts, they quickly referred back to the authenticity cache to reinforce their viewership bond: “You guys know I would never partner with a brand that I didn't fully stand behind, and @premierprotein is one of those brands.” In this way, body positive advocates were observed to carefully weave promotional strategies into their content so that their relatable accessibility is neve interrupted.

In some instances, hashtags were used as both branded promotional material and a community hashtag simultaneously. Some body positive advocates, like Megan Crabbe (@bodyposipanda) and Natasha (@nourishednatasha) have leveraged their influencer status into businesses located in body positive ideology. Both regularly used hashtags that subversively brand their business, for instance, \#nourishmentnotpunishment, \#bopoyoga, and \#bodyposi, while leveraging community hashtags to bring in new viewership. It is this notion of community as commodity, enabled by the use of hashtags and tagging features, that make Instagram users an attractive demographic to advertisers. 
Instagram plays a critical role in the interaction rituals that comprise everyday life. As a global community, Instagram not only opens up the possibility to interact with specific communities, it incentivizes users to deploy architectural features as part of an 'acknowledgement ritual' (Baker \& Walsh, 2018) to achieve visibility, status, and recognition from affirming audiences. All social media platforms are engineered to encourage users to seek recognition and approval, as measurable by metrics such as likes, followers, and comments. One of the primary motivations for employing hashtags is to attract viewers who act as an affirming audience by liking and commenting on one's content. These metrics translate into cultural capital, leveraging users into different tiers of influencer status, directly translating into monetized earning potential; while also functioning as an online acknowledgement ritual through which members of the body positivity community affirm or refute lived experiences and identities.

Top posts reveal those that are considered to be the most popular forms of identity presentation and display. While Instagram's metrics by no means characterize an entire community, they do represent status and recognition. The majority of data content was collected from body positive advocates who are considered mid-size influencers, with followers measured in the tens and hundreds of thousands. Given the established commercialization opportunities on Instagram, it can be assumed that their social media influence translates into earning potential, not including their side business ventures. The presentation of body positivity is choreographed and commercialized to achieve specific readers of the movement acceptance into the online community. 


\section{Depoliticizing Resistance}

Fat activism is unique in that it is creating and reflecting new styles of social change. While limited, the current scholarship of fat activism has demonstrated a clear political process unique to fat activism, including micro, macro, and meta activities (Cooper, 2016). Nevertheless, while fat activism boasts a dominant cultural feature, body positivity fails to produce material benefits due to its apolitical ideology. While academically and culturally affirmed as a subset of fat activism, body positivity's relationship to social justice and resistance is questionable due to its solipsistic individualism. Enacting body positivity online is achieved through the work of personal growth and development, self-knowledge and reflection, and through the enjoyment and appreciation of a diversity of body types. The ratification of this theme is seen in self-care discourses.

Self-care has often been characterized as the practice of taking an active role in the preservation or improvement of one's health, especially in times of great anxiety or stress. Given the current political and economic environment, self-care has emerged as a valuable ideological tool, appealing not only to common sense notions of individual empowerment, but more significantly, its use to neoliberal economic policies to place greater responsibility for health and welfare with individual citizens. Despite self-care's origins in early feminist conceptions of grassroots activism and collective advocacy (Ward, 2015), modern self-care has seen a co-option by governments, consumer markets, and corporate structures to include an apolitical understanding of the self-as-enterprise. While concepts of self-care have been mobilized by policy makers and governments in a deepening of neoliberal objectives to dismantle public 
welfare resources, a less overt, cultural construction of self-care has been found in internet subcultures, including body positivity.

Often constructed as 'self-love', body positivity advocates encourage practices that echo self-help regimes to achieve personal growth and development. Defined simply as having a high regard for one's own wellbeing and happiness (Nehring, Alvarado, Hendriks, \& Kerrigan, 2016), self-love is frequently infused with other body positivity goals, including body acceptance. Within the data assemblage, many accounts still reflect the approach and style of Marilyn Wann's (1998) Fat! So?, a brightly coloured activity book that invited readers to divest from self-hatred and weight loss cycles through craft activities, personal anecdotes, and positive affirmations. The self-care offered by body positivity falls into this realm, where advocates act as inspirational speakers and life coaches, giving their followers guidance in the form of gratitude journals, guided meditations, daily exercise routines, personal mantras, relaxation activities, and yoga practices, just to name a few.

While the majority of advocates indirectly acknowledge the negative effects of diet culture, self-care is the only tool offered, cementing any resistance strategies as purely individual and apolitical in practice. Body positivity's cognitive and emotional solipsism do not account for the ways in which the individual may be bound up in the institutional frameworks of systemic oppression. The intricate and structural realities of diet culture are never discussed except as they relate to eating disorder recovery: "My doctors celebrated me for my extreme weight loss. My friends, family, and the internet (tumblr and instagram) praised me for it. That only fueled the fire. That my worth went up the smaller I got." Otherwise, diet culture and fatphobia often go unnamed, and are instead generalized into a "hard world" that requires the "soft and kind" practices of self-love as a consummate mitigating force. 
In this way, self-love is characterized as the ultimate 'cure'. In describing her history with eating disorders, Natasha (@nourishednatasha) identifies self-love as an “overpowering” force against her disordered eating compulsions: "There are days when the thought of "just starve yourself, you can lose weight' crosses my mind. But the self love + worth overpowers it." Selflove is constructed as a monolithic ideal, promoting transformation fantasies and happy endings to such a degree that negative feelings, and legitimate disorders, are portrayed as mental and emotional hurdles to overcome through cognitive orientation by individuals. The self-hatred so readily acknowledged within the body positivity community is constructed as, at best, an opportunity for entrepreneurial self-improvement, and, at worst, a personal failing, rather than the product of the social world. These feelings are minimized as internal to the individual and something that can be addressed through a simple shift in perspective. Lynley Eilers (@lynleyeilers) reflects this transformation discourse in her content, promoting herself conquering a mountain hike in Colorado as a metaphor for her overcoming negative self-talk: "I made a choice five years ago that I was going to live the life I deserved. To be happy, and to love myself fully, and to try and inspire others to do the same." While Eilers acknowledges her imperfect journey to self-love, including its "ups and downs," she ultimately labels herself as a finished product that can now role model self-love for her followers. Individual attempts at selflove are acceptably imperfect within body positive spaces, but self-love as a concept is continually upheld as a monolithic ideal, ultimately setting its believers up to fail. Conveniently, this self-fulfilling prophecy creates opportunities for consumer solutions.

With self-love constructed as the ultimate remedy to the individualized self-hatred experienced by their followers, body positive advocates were frequently found to offer their 'expert' services as treatment. Woven into their daily content, advocates model their posts after 
traditional advertising campaigns, teasing viewers with generalized self-care strategies to be expanded on if they purchase the products or services offered through their businesses or partnerships. Natasha (@nourishednatasha) brands herself as a \#selflovecoach and preaches about the benefits of daily self-care practices. While Natasha offers "mini self-love tips and trainings" in her daily content, she frequently advertises her "self-care classes" and coaching services as the ultimate source of self-love guidance. Similar to the self-help industry, Natasha frames the authentic self as one who fully commits to the behavioural modification techniques found in her courses, but just out of reach so as to close the sale: "But if you don't start now, then when? Stop wasting time and start loving yourself, boo!” Megan Crabbe (@bodyposipanda), considered a titan in contemporary body positive spaces, similarly promotes her partnership with the Dove Self-Esteem Project using professionalization discourses, characterizing Dove as the "largest global provider of self-esteem education." Through the commodification of self-care practices, the power relationships of capitalism are produced and reinforced in body positive spaces as advocates encourage their followers to submit to, and legitimate, the authority of 'experts'.

With its focus located in behaviour modification, body positivity mimics the self-help industry and the positive psychology movement where systemic inequalities are overlooked and failure is predicated on not having tried hard enough to succeed. This construction of self-care is an understanding of the self-as-enterprise where the notion of individual autonomy serves to depoliticize subjects. Body positivity is grounded in self-love as the ultimate goal, with self-care practices offered as the primary road to self-improvement. Inspirational affirmations and mantras are peppered through the assemblage of content, where users are encouraged to develop an entrepreneurial attitude as they become better versions of themselves. In this way, the self-love 
of body positivity is no different from self-help industries that promote self-improvement through positive thinking and emotional intelligence.

This discourse is further crystallized when self-representation is depoliticized and atomized, with body positive advocates wholly concerned with personal challenges and purely individualized objectives. This apolitical discourse has been so fully adopted by the body positive community that they have become common sense assumptions. Such assumptions and claims promote the power of positive thought to individually overcome the negative emotional consequences of diet culture. This self-love discourse constructs happiness and empowerment as results of cognitive management, with little symptoms afforded to historical, political, or social striations. While the realities of diet culture and fatphobia translate into individual lived experiences, the solutions offered never examine the political, social, and economic reasons for said structures. Instead, users are encouraged to look inward for solutions to the daily pressures of anti-fat stigma.

\section{Commodified Citizenship}

As an emerging locale for social interaction, social media is driven by a specific kind of identity construction. Social media consumers, specifically influencers, often partake in selfmediation in which they construct a highly curated and abridged version of the self. As new digital markets dominate Western economies, online media has transitioned into an exceedingly consumer-centric space. While the original purpose of body positivity may have been supported by supposed democratic spaces found online, as those technologies adopted consumptive objectives, the public identities of advocates shifted according to the direction of platform interfaces. 
As previously demonstrated, Instagram's transition to a commodified platform introduced body positive advocates into an attention economy where competition relied on effective selfbranding. With the growth of sophisticated communication technologies, new media actors were forced to compete across an unprecedented number of screens for increasingly distracted, dispersed, and privatized audiences (Khamis et al., 2017). As attention economies became the new reality, creative thinking was required for how to create lasting, flexible, and evolving relationships with consumers, resulting in the human brand. Self-branding is the process whereby individuals develop a distinctive public image for commercial gain and/or cultural capital (Duffy \& Hund, 2015). The branded self has established its own influencer economy, argued by economists to be a platform from which marginalized individuals, disenfranchised in traditional markets, could compete for social mobility. Designed for public consumption, the human brand introduces critical questions about postmodern notions of identity construction and selfrepresentation.

Each body positive advocate was seen constructing and maintaining their own human brand. Self-branding operates through principles and practices distinctive to 'promotional culture' of advanced consumer capitalism (Khamis et al., 2017). These self-branding principles begin with their account description, in which each advocate defines their brand identity. The majority incorporated body positive identifiers or verbiage, using discoverable hashtags such as \#bodypositive, \#bodyacceptance, and \#selflove. This self-branding process continued through their use of business identifiers and links, with many advertising themselves as plus-size or curve models, linking their representation or business contacts in the description. Similarly, many advocates provided links to their related business ventures, in which they had commodified 
aspects of body positive ideology into speaker series, fitness training services, self-help books, coaching services, and fashion lines.

Each body positive advocate benefitted from a unique public identity that is clearly communicated to consumers, employers, and markets. Through the branding process, body positive advocates have reduced the complexity of the human experience to a clear, marketable identity. Ashley Hartley (@ashleyrosehartley) identifies themselves as a "body confidence” account characterized by "self love, boho vibes [and] beach life." As a California resident, Hartley consistently features herself, and her 'inclusive' clothing line, on sunny beaches and lush terrains. She perfectly represents the hypervisibility so common in body positive spaces, proudly wearing bikinis of every style, modeling how "every body is a bikini body." Hartley’s brand as an effortless California girl is perfect for the brand partnerships she has cultivated with fashion brands like Aerie, Ray Ban, and Free People. Hartley continually promotes values of body confidence and representation, but always blends them with marketing opportunities: "I want to show fashion on a different body type...I am thankful for companies like@ninewest that are helping shine light on innovators and helping women feel confident at all stages of life." Similar to other advocates, Hartley takes every moment to immerse branding opportunities into her content, tagging both products and potential distributors. To position their human brand in competitive markets, advocates must craft their representation to appeal to consumers and potential partners. Body positive advocates frequently internalize practices designed for marketing of commodities, representing a shift in subjectivity construction.

The vigorous practice of consumerism in the data assemblage has demonstrated commercialism as body positivity's primal force, in which the disciplined regulation of the body is facilitated by the purchase of goods and services, and through these transactions proper 
citizenship is enacted. While Western economies have responded to public demands made possible by consumer activism, fashion and beauty industries continue to regulate fat individuals to supplementary engagement roles. Limited access to extended clothing sizes mean that fat people find their bodies neither catered to, nor accommodated, limiting their ability to participate in consumer culture. Body positive advocates were seen subversively challenging hegemonic beauty norms to reframe citizenship to help renegotiate its terms so fat people could experience market privileges. In a sponsored post, Sophie (@98smlc) calls for the athleisure fashion market to "normalize fat bodies," praising the STRONGER label for offering extended clothing sizes and promoting body diversity. Body positive advocates were often seen mobilizing their consumer advocacy, directing their followers to labels and brands that offered extended sizes and body diversity in their advertising campaigns. The commodified activities by body positive advocates succeeded in challenging the prevailing notions of good public citizenship as defined within a neoliberal framework.

\section{Body Positivity as Body Management}

While the body positivity community is characterized as a counterculture to hegemonic beauty standards, its own cultural norms and practices have exposed a rhetoric of choice-driven, bodily-oriented self-improvement in the context of neoliberal citizenship. This style of governance encourages citizen responsibility to empower, monitor, and care for themselves within the private sphere. While historically, neoliberalism has effectively harnessed political, social, economic, and medical structures to manage fat bodies, countercultural spaces such as body positivity communities present a threat to its governance. Fat people are thus targeted by cultural intermediaries in an attempt to mitigate the ideological risk they present. As body 
positivity continues to assimilate into the dominant culture, its advocates present a unique opportunity for body management.

As previously discussed, hashtags are a textual medium that advocates frequently employ to describe the content of their posts, making them discoverable to the public. Instagram hashtags are a way of organizing and, more importantly, categorizing photo and video content to create an anthology of a particular discourse. Outside of the architectural capabilities, body positive advocates were seen engaging in new linguistic development whereby body types were reified into categories. Advocates frequently used new verbiage in the form of hashtags to sequester body types along a spectrum, including \#smallfat, \#midsize, and \#midfat. These terms are thought to originate from the fat acceptance community who categorizes fatness in an attempt to make visible the most marginalized along the fat spectrum. 'Small fat' describes the experience of those individuals at the smaller end of the fat spectrum, usually defined by their privilege in accessing mainstream fashion markets and healthcare services without difficulty. 'Midfat' still represents those at the smaller end of the spectrum, but includes those that struggle to find clothing in straight-sizes, and experience a modicum of oppression in public spaces and health care services. Those identified as 'infinifat' can no longer engage in normative fashion markets, and are forced to shop at plus-size clothing retailers or seek out custom-made options. Further, those who are categorized as infinifat face intense institutional sizeism, with size accessibility interfering with every aspect of daily life.

Language plays a critical role in the formation of the self, thought, and subjectivity. This language development along with an array of other factors, such as culture, the historical understanding of social concepts, interpersonal relations, and space, all lead to the expression of a range of identities, all of which are socially constructed. Originally coined by fat acceptance 
activists, the spectrum of fat is an act of 'meaning making' in which the semiotic and symbolic, coupled with biology and social relations, develop an interpretation of cultural affairs. Fat activists engaged in complementary work to link signs and signifiers together in a series, creating a structure that both represents and challenges institutional sizeism. While these terms were originally coined to describe the intersecting oppressions experienced along the spectrum of fatness, body positive advocates do not engage these categories as political expression. Instead, they mobilize these categories as a tool of consumerism and body management. This new language rhetoric is often limited to the use of hashtags, with no political context given. Maggie (@midsizemagpie) has incorporated the midfat category into her human brand, embodying contemporary fatshionista values of consumer activism and postfeminist entrepreneurship. While her relationship with capitalism is more complex as an influencer whose brand identity is located in thrift fashion, Maggie still operates through a commodified activism, equating consumer accessibility with citizenship: "As a midsize/plus size gal I know the anxiety of trying to find secondhand clothes. But there are absolutely options out there for you....have a gander at @goodshoplondon.” Maggie, and other accounts like hers, speak of a capitalist strategy of treating countercultural expression as a resource for taking over and market back to consumers as a maker of identity. According to Kristeva (cited in Moffatt, 2019), this consumerist approach to symbols results in a narrowed space to explore meaning; compromising the original purpose of its creation. Whilst fashion as activism became a part of an imperative to create profit, what was lost in this process was the original call to critique social systems, instead arguing that corporate commodification is activism.

As a self-described "almost fat girl," Maggie fails to embody the critical reflexivity necessary for engaging with the fat spectrum. Similar to Maggie, Abi (@midsizegal) and Meg 
(@midsizemeg) consistently position themselves against those who are fatter than them, failing to acknowledge their intersecting privileges compared to those further along the fat spectrum. Without critical context, this verbiage is limited to operating as neoliberal categorization, mimicking the hierarchical diet culture it seeks to counter. The co-option of the language of emancipatory and collective campaigns into the service of a neoliberal agenda transforms the fatness spectrum into a biopolitical tool.

Body positive advocates echo a model of neoliberal citizenship that replaces external forms of government where internal regulators deem success based on the ability to self-govern. Body positive accounts were only seen to engage the smaller, more privileged end of the fatness spectrum. Said categories were limited to \#smallfat or \#midsizefat, demonstrating how, cushioned by messages of authenticity, exposure, and transformation, body positive content frequently functions as spaces where a particular mode of acceptability is modeled to those liminal bodies that previously existed in the realm of not-quite (thin enough, large enough). While those who identify as small fat and midfat may have been excluded from normative fashion markets that privilege thin(ner) beauty ideals, the current use of the fatness spectrum is an attempt to assimilate rather than liberate, further oppressing those who live in larger bodies. This practice is simply adapting and appropriating new media technologies and communication practices to the needs and interests of the dominant group.

Body positive advocates attempt to walk the line between assimilation and liberation, resulting in a kind of apologetic embodiment of fatness and fat activism. Advocates frequently model and encourage exercise as part of a "holistic self-care routine." They often show themselves engaging in daily workout routines and 'clean eating' habits; promoting and conforming to ideals of healthism, and the responsible self-management and monitoring of one's 
body. This kind of identity construction is evidence of LeBesco's (2004) 'will to innocence' in which fat people are constructed as not responsible for their fatness. Advocates present themselves as correctly-behaved, blame-free, healthy citizens with regard to their exercise and eating habits. While advocates may be fat, they are in no way unhealthy. This kind of activism is concerned with the promotion of fat people as healthy, and therefore as morally good as their normatively-sized counterparts. In this way, body positive advocates reinforce the neoliberal discourse that their healthy body is equated with the morally-worthy citizen, one who exercises discipline over their body, extending the reach of the state, and sharing the burden of governance. Thus, through the adoption of neoliberal citizenship requirements, body positive advocates replicate mainstream ideals of health and wellness while maintaining the surveillance and regulation of fat bodies.

LeBesco (2004) argues that, in rare occurrences in which fatness is considered an acceptable identity, there are clear differentiations of 'good' and 'bad' fat. Often referred to as the 'good fatty' trope, fatness is acceptable only to a certain degree, and not embraced without exception. These exceptions often intersect with other forms of identity and oppression. Body positive advocates enacted a certain 'percentage of disorder' while largely maintaining characteristics of the hegemonic ideals. This primarily played out in the form of bodily aesthetics and race.

Similar to the first introductions of "healthy, sleek...and feminine" (Strings, 2019) models of beauty in America during the late eighteenth century, body positivity capitalizes on walking the line of weight, race, and aesthetics to represent the 'right' model of beauty. Akin to the academic disconnect of body positivity from its fat acceptance roots, race has historically been detached from fat studies research, producing a limited understanding of fat embodiment. Strings 
(2019) expertly links the stigmatization of fatness in Western societies to anti-Black racism where the discourse of fatness as 'savage' and Black worked to denigrate Black women and cement white thinness as the ideal. By the late eighteenth century, media arbiters of fashion and beauty had transitioned from the lush forms of the Renaissance to a thinner figure, denouncing the fatness of the "savage races" and exalted the "streamlined aesthetic" of white models (Strings, 2019). These new role models were expected to balance the unachievable line between feminine curves and the "vigorous leanness" necessary of a new neoliberal ideal (Strings, 2019). This unattainable ideal is commonly found in body positive spaces, where fatness is only acceptable as a hyper-feminized, curvy physique trademarked by evolutionarily-desired physical features. Further, the exaggerated hourglass figure, trademarked by large bust and hips has been appropriated from a figure typically associated with Black embodiment, and then weaponized against Black communities. This kind of embodiment, however, is only acceptable when accompanied by traditional representations of white femininity, and a rigorous dedication to health and exercise. Through assimilationist spaces like body positivity, hegemonic structures continue to manage Black bodies by repackaging healthism and fat activism to control dissenting communities.

Body positivity reproduces such ideals regarding weight, race, and aesthetics through a kindred preoccupation with white Eurocentrism. Most of the body positive advocates appeared to be white, echoing the historic emphasis on body regulations emanating from white Western female culture. Those that did not identify as white were seen to be of lighter complexions, replicating previous body positive campaigns that offered a limited presentation of diversity (Taylor et al., 2016). Critics have frequently identified the propensity of influential body positive accounts to depict conventionally attractive white women, often excluding other marginalized 
bodies, such as diverse ethnicities and gender non-conforming bodies. Thin beauty ideals and fatphobia have historically mobilized to craft and legitimate race, sex, and class hierarchies. The pasteurized fat activism in the form of mainstream body positivity has kept activists from understanding and confronting larger structures of oppression, producing a "defanged fat activism repackaged suitable only for corporate use and coddling the feelings of thin, ablebodied, cisgender, white women" (Cwynar-Horta, 2016).

\section{Discussion}

While academic scholarship has situated body positivity as a spontaneous by-product of democratic online spaces, the movement in its current form is more attributed to Marilyn Wann's (1998) landmark publication, Fat! So? Despite fat activism's well-established history as a radical civil rights movement, body positivity's break with its grassroots origins came in the form of a colourful activity book. With its upbeat tone and peppy language, Wann (1998) contrasted earlier resistance strategies by offering a compelling guide to divesting from self-hatred. One can find her fingerprints throughout the majority of contemporary body positivity, where self-love and body acceptance are preached with a cheerful and almost evangelical style.

This creative approach to fat activism was stocked by its shift into online spaces. Operating in a media environment that held the promise of being more democratic and egalitarian, one would presume that a new politics of meaning would undermine and replace long-standing power relations. Unfortunately, body positivity followed other social movements where emerging countercultures were adapted and appropriated to the needs and interests of the dominant group (De Perthuis \& Findlay, 2019). Examination of contemporary body positivity 
revealed existing power relations of capitalism where consumer culture is embedded and reproduces ideals of the hegemonic majority.

Though body positivity advocates seek to position themselves against idealized beauty norms, they easily align a postfeminist discourse with a corporate imperative. Elias and Gill (2018) argue that postfeminism is a 'double entanglement' which facilitates both a doing and undoing of feminism. In postfeminist societies, women are constructed as active, autonomous, and empowered, effectively replacing the need for collective social activism. Both postfeminism and neoliberalism are structured according to a robust individualism that has almost entirely replaced the social or political context. Body positivity's commitment to self-care and self-love as primary mechanisms for change effectively desocialized and depoliticized the self in what Nehring, Alvarado, Hendriks, and Kerrigan (2016) describe as the 'thin self'. While anti-fat stigma does have interpersonal consequences, this kind of solipsism constructs an apolitical selfrepresentation. Produced through self-help narratives, the thin self is concerned with purely personal challenges and accomplishing purely individual objectives. Body positive advocates are clearly implicated in the construction of the thin self online through the promotion of atomistic and emotional individualism, which stresses the desire for personal choice, responsibility, and self-reliance. These assumptions co-create and program the thin self by recognizing the realities of everyday stress and anxiety caused by institutional fatphobia while suggesting solutions. Yet, these solutions never examine the political, social, and economic reasons for these feelings; instead, the thin self looks inward, seeking ways to make itself adaptable and malleable to the strains of the neoliberal moment, rather than looking outward towards social change. The implication of such an apolitical representation in a movement that supposedly desires social 
change is a legitimation of contemporary capitalist ideology, where the collective construction of socio-political change remains limited.

With this rise in postfeminism and neoliberalism, body positive advocates confidently embrace commodity culture. The guise of entrepreneurial agency is often measured in terms of commodity consumption. Given the large role consumer culture plays in body positive spaces, wider political mobilization and social change become secondary to entrepreneurial selfimprovement. While consumer activism could be considered a necessary evil, Kristeva (cited in Moffatt, 2019) reminds us that the central purpose of Western commercial culture has been the spread of consumerism, calling into question any social movement that does not engage an anticapitalist critique.

This neoliberal framework requires the cultivation and regulation of a human brand. While these new digital markets are glamorized as egalitarian spaces for a reconstruction of traditional power structures to benefit marginalized groups, this operates as a convenient pretense for a new labour force befitting capitalist exploitation. Overlapping with self-help narratives, body positive advocates enact characteristics of the 'belabored self' (McGee, 2015), a personality type that emerged as a result of Western society's therapeutic turn, economic insecurity, precarious labour market, and restructuring of social welfare programs. Previously excluded and undervalued in traditional markets, body positivity advocates are drawn by a narrative of entrepreneurial freedom, all while absorbing the risks and costs of a diminished safety net. These alternative markets require workers to constantly and continually work on themselves in efforts to remain employable, with self-improvement offered as the only reliable insurance against economic insecurity. The contention that social media platforms stimulate a democratic culture denominated by creative amateurs to provide a space for new entrepreneurial 
freedom has been countered by vehement criticism. While body positive advocates have the opportunity to monetize their online activities, the intersection of social media engagement as leisure activity and profit has resulted in amusement becoming an extension of labour under late capitalism. The self-branding activities of body positive advocates exist in this philosophical grey area, where individuals engage in virtual labour to form digital subjectivities while making themselves legible to corporate productivity goals. In this way, commercial interests hijack these online spaces that are meant to be democratic. The blend of postfeminism and neoliberalism was further implicated in that both are built around understandings of entrepreneurial modes of self centered on transformation. Implicit in narratives of self-branding and entrepreneurial freedom is the assumption that the self can be transformed through behaviour modification. Body positive spaces, and business, are built on foundations of self-help narratives, developing their own common-sense assumptions informed by neoliberal tenets.

These Foucauldian understandings of postfeminism and neoliberalism are enveloped in demonstrations of extensive surveillance of the self. The immediacy and authenticity narratives infused in the architecture of Instagram's platform required intensive and extensive surveillance of the self. Blended with the hypervisibility necessary for entry into body positive spaces, advocates were constantly submitting themselves to surveillance. This creative labour whereby body positive advocates use photographic technologies to enact hypervisibility is normatively demanded in online body positive spaces. Anything less is considered a failure to achieve selflove, which, for a body positive advocate imbibed with professional status, could mean loss of income and cultural capital. 


\section{IMPLICATIONS FOR SOCIAL WORK}

As a profession that considers individual experiences as contexts within systems and structures, social work must consider the implications of bodies that are perceived as deviant on the basis of size. Non-normative identities generally have had a home within social work, with race and class named within codes of ethics, and ability and sexual orientation enthusiastically unpacked within social work literature. Fatphobia has anecdotally been characterized as the last 'acceptable' form of discrimination. This has been demonstrated academically, with Mik-Meyer (2010) arguing that "the overweight body remains under-theorized in social work." The limited literature that does explore the implications of fat bodies for social work begins from an individualistic clinical model. A greater concern is that very little social work research seriously considers the structural nature of fat oppression, in stark contrast to other sites of structural discrimination.

Then the question shifts to whether fat bodies experience stigma in as profound and quantifiable ways, compared to other identity markers. There is ample evidence to suggest that fat bodies experience daily oppression. Anti-fat prejudice is defined as a negative attitude toward, belief about, or behaviour against people perceived as fat (Matacin \& Simone, 2019). Fat people are denied health care and employment, and are paid less than their thin counterparts. Fat people have limited access to post-secondary education and economic mobility, with fat people admitted to university and college programs in lower numbers than thinner applicants. Fatphobia has a documented social stronghold, with children recorded as fearing weight gain from as young as five years old (Friedman, 2012). Fat stigma greatly impacts mental wellness, with fat children more likely to attempt suicide (Friedman, 2012). 
With this research exploring the intersection of social justice and technology, it is of greater concern that social work has historically shied away from discussions of technology; regulating it to a supplementary position as a tool for outreach and dissemination without acknowledging how social media and other communication technologies have transformed the relationship between social workers and service users. Any research considerations have been limited to the use of social media, and other online technologies in social work practice as they relate to ethical and practical considerations. Social work is a field that needs to move beyond the functional, and link their knowledge of the complex interplay between discourses that underpin daily practice, such as those related to power, subjectivity, and embodiment, to social media spaces.

Social workers are bound to "oppose prejudice and discrimination against any person or group of persons, on any grounds, and specifically challenge views and actions that stereotype particular persons or groups" (CASW, 2005), and as a result have a responsibility to pay attention to the experiences of fat people and participate in the fight against fatphobia. Given the interpersonal impacts of living with anti-fat prejudice, social work practitioners are bound to connect with service users that are actively dealing with those lived realities. While some social work practitioners have drawn on the 'health at every size' philosophy (Matacin \& Simone, 2019) to encourage a politically aware and conscientized response to fat oppression with service users, most of these therapeutic interventions are from an individualist clinical setting. Unfortunately, as with other forms of oppression, social work is not immune from enacting fatphobia in their professional practice.

A historical analysis of social work shows the many ways that the profession began as an agent of social control and moral regulation (Friedman, 2012). Social workers have historically 
been involved with providing docile bodies and compliant subjects to the state, rather than with social change. It is arguable that contemporary social work practice is about ensuring compliance rather than fostering social justice. The social control role of social work has historically relied upon scientific and medical discourse for justification. Social workers practicing in these fields may be especially implicated in 'helping' individuals and communities respond to the perceived dangerous weight patterns for societal good, framed in neoliberal rhetoric around the need for healthy and cost-effective societies (Friedman, 2012). Given the contemporary values of social work as a profession meant to emphasize social justice, it is critical that social workers engage with fat activism movements using a critical lens.

This relevance is made explicit by the ease with which social workers may be co-opted into opposing fat bodies and participate in the controlling of fat individuals through said social movements. If we problematize this task with the understanding of technology as central to contemporary communication, and thus the construction of social relationships and social movements, social workers must interrogate the influence of neoliberal structures on such social tools (Boddy \& Dominelli, 2016). Social media and other communication technologies have emerged and been defined by the context of neoliberalism and rapid technological advancement to develop a highly networked society. Given its role in contemporary communication, understanding that neoliberalism has changed the relationship between the individual citizen and the state enables practitioners to appreciate the capitalist social relations embedded in the daily routines of their service users. This is especially critical when social workers consider online relationships and interactions as both embodied and contextualized to inform offline relationships, behaviours, and events. 
Considering social work's relationship with social justice, specifically social change movements, social work research and practitioners should be actively engaged in the changing landscape of social resistance. As with other forms of communication, social movements have actively engaged in social media spaces (Coban, 2016; Hwang \& Kim, 2015; Kidd \& McIntosh, 2016), feeling the impacts of its architecture. While body positivity has transitioned to offline spaces, the majority of its presence is located online, acting as a canary in the coalmine for current and future movements as they engage in this highly commodified platform.

\section{CONCLUSION}

While free market ideals retain a canonical presence in contemporary culture, progressive social ideas have always been readily incorporated into capitalist marketing and promotional campaigns. This phenomenon of 'commodifying dissent' is not unusual, and has been argued to constitute a key feature of contemporary capitalist culture. Modern body positivity advocates for 'hip consumerism' where rebellion against the system is understood as rebellious consumption, as consumers are able to purchase commodities that express their critiques even as they remain deeply entrenched within capitalist systems. Dedicated followers purchase clothing identifying themselves as "disobedient [women]" with thick thighs that save lives, effectively expressing their critiques of an unpopular system while remaining 'empowered' citizens of a postfeminist consumer culture. This false consciousness encourages conformity as countercultural resistance has successfully and productively merged with entrepreneurial culture. Body positivity as a postfeminist movement is depoliticizing, creating spaces for attention to fat issues, supplanting 
and substituting for critical and active forms of the political engagement necessary for true social change.

Though an argument could be made for taking a harm reductive approach to fat activism within a neoliberal, capitalist society, embracing a unilateral commodification of fat activism has dangerous consequences that move beyond fat issues. The use of body positivity in advertisements could influence audiences to trust corporations erroneously. Assuming that corporations will do the political work for them, individuals may feel liberated from the need to form their own critiques and modes of resistance. Regardless, devolving oneself from the responsibility to engage in critical discussions, regardless of the inconsistencies, ironies, and contradictions that may arise, is to create a depoliticized and disengaged population vulnerable to further oppression and marginalization. While this research may resolve with more questions than answers, it is our hope that a more critical gaze was directed at a burgeoning cultural center, inspiring future conversations. 


\section{REFERENCE LIST}

Adwoa, A. A., \& Ricciardelli, R. (2015). Shaping the online fat acceptance movement: Talking about body image and beauty standards. Journal of Gender Studies, 24(4), 453-472. DOI:10.1080/09589236.2015.1028523

Arribas-Allyon, M., \& Walkerdine, V. (2008). Foucauldian discourse analysis. In C. Willig \& W. S. Rogers (Eds.), The SAGE handbook of qualitative research in psychology (pp. 91108). London, England: Sage Publications

Baker, S., \& Walsh, M. J. (2018). 'Good morning fitfam': Top posts, hashtags and gender display on Instagram. New Media \& Society, 20(12), 4553-4570.

DOI:10/1177/1461444818777514

Boddy, J., \& Dominelli, L. (2016). Social media and social work: The challenges of a new ethical space. Australian Social Work, 70(2), 172-184.

DOI:10.1080/0312407X.2016.1224907

Bombak, A. E., Meadows, A., \& Billette, J. (2019). Fat acceptance 101: Midwestern American women's perspective on cultural body acceptance. Health Sociology Review, 28(2), 194-208. DOI:10.1080/14461242.2019.1604150

Bratu, S. (2019). Can social media influencers shape corporate brand reputation? Online 
followers' trust, value creation, and purchase intentions. Review of Contemporary Philosophy, 18, 154-160. DOI:10.22381/RCP18201910

Cain, P., Donaghue, N., \& Ditchburn, G. (2017). Concerns, culprits, counsel, and conflict: A thematic analysis of 'obesity' and fat discourse in digital news media. Fat Studies, 6(2), 170-188. DOI:10.1080/21604851.2017.1244418

Cameron, L. (2019). The 'good fatty' is a dancing fatty: Fat archetypes in reality television. Fat Studies, 8(3), 259-278. DOI:10.1080/21604851.2019.1549400

Canadian Association of Social Workers (2005). Code of Ethics. Retrieved from https://www.casw-acts.ca/sites/default/files/attachements/casw_code_of_ethics.pdf

Coban, B. (Ed.) (2016). Social media and social movements: The transformation of communication patterns. Lanham, MD: Lexington Books

Cohen, R., Fardouly, J., Newton-John, T., \& Slater, A. (2019a). \#BoPo on Instagram: An Experimental investigation of the effects of viewing body positive content on young women's mood and body image. New Media \& Society, 21(7), 1546-1564. DOI:10.1177/1461444819826530

Cohen, R., Irwin, L., Newton-John, T., \& Slater, A. (2019b). \#bodypositivity: A content analysis of body positive accounts on Instagram. Body Image, 29, 47-57. 
DOI:10.1016/j.bodyim.2019.02.007

Cook, K., \& Wilson, C. L. (2019). Representations of fatness in Parents magazine: A critical discourse analysis. Fat Studies, 8(3), 320-333. DOI:1080/21604851.2019.1574509

Cooper, C. (2016). Fat activism: A radical social movement. Bristol, UK: Hammer On Press.

Cwynar-Horta, J. (2016). The commodification of the body positive movement on Instagram. Stream: Interdisciplinary Journal of Communication, 8(2), 36-56. http://journals.sfu.ca/stream/index.php/stream/article/view/203

Daniels, J. (2009). Rethinking cyberfeminism(s): Race, gender, and embodiment. Women's Studies Quarterly, 37(1-2), 101-124. https://doi.org/10.1353/wsq.0.0158

De Perthuis, K., \& Findlay, R. (2019). How fashion travels: The fashionable ideal in the age of Instagram. Fashion Theory, 23(2), 219-242. DOI:10.1080/1362704X.2019.1567062

Dickins, M., Browning, C., Feldman, S., \& Thomas, S. (2016). Social inclusion and the fatosphere: The role of online weblogging community in fostering social inclusion. Sociology of Health \& Illness, 38(5), 797-811. DOI:10.1111/1467-9566.12397

Duffy, B. E., \& Hund, E. (2015). 'Having it all' on social media: Entrepreneurial femininity and self-branding among fashion bloggers. Social Media + Society, 1(2), 1-11. 
DOI:101177/2056305115604337

Elias, A. S., \& Gill, R. (2018). Beauty surveillance: The digital self-monitoring cultures of neoliberalism. European Journal of Cultural Studies, 21(2), 59-77.

DOI:10.1177/1367549417705604

Elliot, C. D. (2007). Big persons, small voices: On governance, obesity, and the narrative of the failed citizen. Journal of Canadian Studies, 41(3), 134-206.

https://doi.org/103138/jcs.41.3.134

Evans, B., \& Colls, R. (2009). Measuring fatness, governing bodies: The spatialities of the Body Mass Index (BMI) in anti-obesity politics. Antipode, 41, 1051-1083.

DOI:10.1111/j.1467-8330.2009.00706.x

Evans, N. J., Phua, J., Lim, J., \& Jun, H. (2017). Disclosing Instagram influencer advertising: The effects of disclosure language on advertising recognition, attitudes, and behavioural intent. Journal of Interactive Advertising, 17(2), 138-149.

DOI:10.1080/15252019.2017.1366885

Featherstone, M. (2007). Consumer culture and postmodernism. London, UK: Sage Publications.

Foucault, M. (1984). The ethic of care for the self as a practice of freedom. Interview by Raul 
Fornet-Betancourt, Helmut Beacker, \& Alfredo Gomez-Muller. Boston University, Boston, MA.

Foucault, M. (1990). The history of sexuality. New York: Vintage Books.

Friedman, M. (2012). Fat is a social issue: Fat bodies, moral regulation, and the history of social work. Intersectionality: A Global Journal of Social Work Analysis, Research, Policy, and Practice, 1, 53-69. https://journals.library.mun.ca/oja/index.php/IJ/article/view/350

Gurrieri, L., \& Cherrier, H. (2013). Queering beauty: Fatshionistas in the fatosphere. Qualitative Market Research, 16(3), 276-295. DOI:10.1108/13522751311326107

Henderson, M., Johnson, N. F., \& Auld, G. (2013). Silences of ethical practice: Dilemmas for researchers using social media. Educational Research and Evaluation, 19(6), 546-560. http://dx.doi.org/10.1080/13803611.2013.805656

Hwang, H., \& Kim, K. (2015). Social media as a tool for social movements: The effects of social media use and social capital on intention to participate in social movements. International Journal of Consumer Studies, 39, 478-488. DOI:10.1111/ijcs.12221

Kendall, G., \& Wickham, G. (1999). Using Foucault's methods. London, England: Sage Publications. 
Khamis, S., Ang, L., \& Welling, R. (2017). Self-branding, 'micro-celebrity' and the rise of social media influencers. Celebrity Studies, 8(2), 191-208.

DOI:10.1080/19392397.2016.1218292

Kidd, D., \& McIntosh, K. (2016). Social media and social movements. Sociology Compass, 10, 785-794. DOI:10.111/soc4.12399

Kwan, S. (2009). Framing the fat body: Contested meanings between government, activists, and industry. Sociological Inquiry, 79(1), 25-50. DOI: 10.111/j.1475-682X.2008.00271.x

LaMarre, A., \& Rice, C. (2017). Hashtag recovery: \#EatingDisorder recovery on Instagram. Social Sciences, 6(68), 1-15. DOI: 10.3390/socsci6030068

LeBesco, K. (2004). Revolting bodies? The struggle to redefine fat identity. Boston, MA: University of Massachusetts.

LeBesco, K. (2011). Neoliberalism, public health, and the moral perils of fatness. Critical Public Health, 21(2), 153-164. DOI: 10.1080/09581596.2010.529422

Lupton, D. (2017). Digital media and body weight, shape, and size: An introduction and review. Fat Studies, 6(2), 119-134. DOI: 10.1080/21604851.2017.1243392

Lupton, D. (2018). Fat. New York, NY: Routledge. 
Matacin, M. L., \& Simone, M. (2019). Advocating for fat activism in a therapeutic context. Women \& Therapy, 42(1-2), 200-215. DOI: 10.1080/02703149.2018.1524071

Markham, A., \& Buchanan, E. (2018). Ethical decision-making and internet research. Retrieved from https://aoir.org/reports/ethics2.pdf (Accessed 6 December 2019).

Micheletti, M., \& Stolle, D. (2008). Fashioning social justice through political consumerism, capitalism, and the internet. Cultural Studies, 22(5), 749-769.

DOI: $10.1080 / 09502380802246009$

Mik-Meyer, N. (2010). Putting the right face on a wrong body: An initial interpretation of fat identities in social work organizations. Qualitative Social Work, 9(3), 385-405. DOI:10.1177/1473325010367817

Moffatt, K. (2019) Postmodern social work: Reflective practice and education. Toronto, ON: Columbia University Press.

Moffat, K., Panitch, M., Parada, H., Todd, S., Barnoff, L., \& Aslett, J. (2016). "Essential cogs in the innovation machine": The discourse of innovation in Ontario educational reform. Review of Education, Pedagogy, and Cultural Studies, 38(4), 317-340.

DOI: $10.1080 / 10714413.2016 .1203680$ 
Nehring, D., Alvarado, E., Hendriks, E., \& Kerrigan, D. (2016). Transnational popular psychology and the global self-help industry: The politics of contemporary social change. London, UK: Palgrave MacMillan.

Rothblum, E. D., Solovay, S., \& Gingras, J. R. (2009). The fat studies reader. New York: New York University Press.

Sam, C. H. (2019). Shaping discourse through social media: Using Foucauldian discourse analysis to explore the narratives that influence educational policy. American Behaviouralist Scientist, 63(3), 333-350. DOI:10.1177/0002764218820565

Sastre, A. (2014). Towards a radical body positive: Reading the online 'body positive movement.' Feminist Media Studies, 14(6), 929-943.

DOI:10.1080/14680777.2014.883420

Scaraboto, D., \& Fischer, E. (2013). Frustrated fatshionistas: An institutional theory perspective on consumer quests for greater choice in mainstream markets. Journal of Consumer Research, 39(6), 1234-1257. DOI: 10.1086/668298

Schops, J. D., Kogler, S. K., \& Hemetsberger, A. (2020). (De-)stabilizing the digitized fashion market on Instagram: Dynamics of visual performative assemblages. Consumption Markets \& Culture, 23(2), 195-213. DOI: 10.1080/10253866.2019.1657099 
Smith, E. (2019). Fat tactics: The rhetoric and structure of the fat acceptance movement. Lanham, MD: Lexington Books.

Strings, S. (2019) Fearing the black body: The racial origins of fat phobia. New York, NY: New York University.

Taylor, J., Johnston, J., \& Whitehead, K. (2016). A corporation in feminist clothing? Young women discuss the Dove 'real beauty' campaign. Critical Sociology, 42(1), 123-144. DOI: $10.1177 / 0896920513501355$

Van Dijck, J. (2009). Users like you?: Theorizing agency in user-generated content. Media, Culture \& Society, 31(1), 41-58. DOI:10.1177/0163443708098245

Wann, M. (1998). Fat! So?: Because you don't have to apologize for your size. Berkley, CA: Ten Speed Press.

Ward, L. (2015). Caring for ourselves?: Self-care and neoliberalism. In Ward, L., Barnes, M., Brannelly, T., \& Ward, N. (Eds.), Ethics of care: Critical advances in international perspective (pp. 25-56). Bristol, UK: Bristol University Press. DOI: $10.2307 /$ j.ctt $1 \mathrm{t} 89 \mathrm{~d} 95.8$

Webb, J. B., Vinoski, E. R., Bonar, A. S., Davies, A. E., \& Etzel, L. (2017). Fat is fashionable and fit: A comparative content analysis of Fatspiration and Health at Every Size 
Instagram images. Body Image, 22. 53-64. DOI: 10.1016/j.bodyim.2017.05.003

Webb, J. B., Thomas, E. V., Rogers, C. B., Clark, V. N., Hartsell, E. N., \& Putz, D. Y. (2019). Fitspo at every size? A comparative content analysis of \#curvyfit versus \#curvyyoga Instagram images. Fat Studies, 8(2), 154-172. DOI:10.1080/21604851.2019.1548860

Willig, C. (2001). Introducing qualitative research in psychology: Adventures in theory and method. Buckingham, UK: Open University Press.

Wright, J., \& Hardwood, V. (2019). Biopolitics and the obesity epidemic: Governing bodies. New York, NY: Routledge. 